\title{
Teatralidade e caricatura na sátira bordaliana contra a censura
}

\author{
Maria Virgílio Cambraia Lopes
}

Na linguagem, a censura aparece, com frequência, associada ao campo metafórico da morte violenta: as imposições censórias são designadas como "atentados"; os censores são apelidados de "algozes", de "carrascos", de "coveiros"; a liberdade "morre" ou "agoniza". Tais designações, que revelam um entendimento da censura como destrutiva da vida, não são mera retórica. Radicam na experiência amarga de quotidianos adversos e exprimem sentimentos de repulsa pelo ataque a um dos direitos mais elementares - o da livre expressão - em cuja defesa sempre se ergueram as artes, em todas as épocas e nos mais variados contextos, por vezes dando as mãos de forma criativa. Foi o que sucedeu entre caricatura e teatro, na sociedade portuguesa fino-oitocentista, nos desenhos satíricos de Rafael Bordalo Pinheiro.

$\mathrm{Na}$ imagem intitulada "A liberdade de imprensa. Colóquio dos coveiros", Rodrigues Sampaio (Ministro do Reino) e António Arrobas (governador civil de Lisboa) são os coveiros que enterram a Liberdade. Na véspera, fora publicada uma portaria que restringia a liberdade de imprensa. 0 desenho, que representa um enterramento e tem como "cenário" um cemitério, concretiza o imaginário que associa a censura à aniquilação da vida humana e, de forma teatral, dá expressão plástica à metáfora da "morte da liberdade". Bordalo apropria-se de uma das "páginas sem sol de Hamlet" (Ivens 1942: 5), uma cena de grande espectacularidade em palco, e traz à memória do observador a famosa passagem que inicia o acto $V_{\text {, em }}$ que os coveiros preparam o funeral de Ofélia. A partir desta cena - e prolongando o que sucede na peça em que, como é sabido, esta situação não aparece -, Bordalo mostra os coveiros a enterrarem a figura feminina da Liberdade. No solo, em primeiro plano, vêem-se uma pá, uma caveira e a cova, detalhes realistas que contribuem para o impacto emocional da imagem. A figura alegórica da liberdade é uma mulher de branco, inerte, com a cabeça tombada para trás, os braços pendentes e as mãos já dentro da cova. A sua imagem, profundamente trágica, contrasta com o sorriso de satisfação que irradia do rosto do chefe da polícia.

0 caricaturista não deixa nada ao acaso e as mangas de Arrobas, responsável pela portaria proibitiva e obreiro simbólico da cova, estão arregaçadas. Na imagem, o observador percepciona a dupla entidade actor/ personagem: reconhece os "actores", identifica as personagens que eles "interpretam" e o jogo do "fazer de conta" que o desenho institui. A disposição das personagens na folha é feita de um modo que sinaliza a contracena no teatro: os dois responsáveis políticos olham-se com cumplicidade, as suas figuras interagem e simulam praticar uma acção. 0 pano de fundo do desenho - as sombras de um cemitério, com as árvores e as corujas - é muito semelhante aos cenários da peça no tempo. 0 referente teatral da caricatura está muito próximo do público: a ópera Hamlet de Ambroise Thomas está em cena, nesse ano, no São Carlos e nos círculos intelectuais a tradução de Hamlet, feita pelo rei D. Luís, é tema de discussão. Numa época em que o teatro é uma arte hegemónica, 0 público vê-se diante de um universo bem conhecido e, tratando-se de Hamlet, o efeito do desenho redobra, já que o observador é induzido a associar as medidas censórias ao mundo sanguinolento e trágico da peça. Na imagem, a metáfora do teatral é enformada por alguns dos procedimentos habituais do desenho caricatural: os contrastes - a silhueta feminina, delicada e flexivel, contrapondo-se às figuras masculinas desajeitadas e boçais que a seguram - contribuem para a percepção da intensidade dramática; e, na legenda, o diálogo estruturase como as réplicas de um texto dramático:

\footnotetext{
- Achas que estará bem morta?

- Com as últimas vinte querelas de ponta e mola que lhe espetámos no ventre e com a bola da portaria proibitiva que Ihe fizemos engolir, acho que não temos senão este derradeiro dever que cumprir. Toca a enterrá-la!

- De profundis.
}

A linguagem popular - querelas de "ponta e mola", "espetar no ventre" "a bola... que Ihe fizemos engolir" reforça o elo de ligação com a realidade repressiva bem conhecida do observador. A caricatura "dialoga", em simultâneo e humoristicamente, com a peça teatral e com a realidade política, servindo-se de alusões visuais muito precisas que, com grande poder de sintese, fazem desenrolar uma meada de fios significativos: o mocho, à esquerda, é o "espectro" (ou não esteja a imagem a citar uma peça de espectros ...), mas 0 espectro era também 0 título do jornal de que Rodrigues Sampaio fora director (em 1846/1847) e que se tornara uma bandeira na luta política contra a opressão e a censura. Ficara famoso por aparecer sistemática e misteriosamente nas secretárias dos responsáveis ministeriais, cuja política denunciava. Dai o seu nome. 0 espectro que, no passado, fora um símbolo da liberdade de imprensa, é, na imagem do presente, assinalado por uma aparição fantasmática que denuncia a prepotência do antigo jornalista. A gravura
Maria Virgílio Cambraia Lopes é investigadora do CET e doutoranda em Estudos de Teatro preparando a tese Rafael Bordalo Pinheiro: Imagens e Memórias de Teatro. As suas principais áreas de interesse são a caricatura, a iconografia teatral, e a história do teatro. 


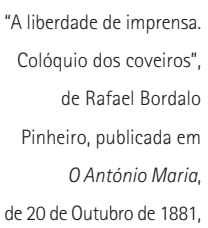

"Venha de lá esse fel",

de Rafael Bordalo

Pinheiro, publicado em

O António Maria

7 de Julho de1881, p. 216

Rafael Bordalo

caricaturara Fontes,

mostrando-o como o

homem dos sete

instrumentos.

${ }^{2}$ V. libreto da Favorita de

Donizetti, segundo

tradução de Francesco

Janetti e Calisto Bassi do

francês, trad. Eduardo

Saló, Lisboa, Editorial de Noticias, 1984, p. 116. activa toda uma rede de significados que têm como eixo a peça de teatro. Analogamente ao que sucede em Hamlet, também um espectro assombra o presente de Rodrigues Sampaio..

Na sátira bordaliana, os desenhos entrelaçam-se de modo a criar ficções. Uns meses depois, na página intitulada "Venha de lá esse fel!", Rafael Bordalo, alvo de perseguição, autocaricatura-se suplicante perante o mesmo Rodrigues Sampaio, que cavalga a caveira d'O espectro. De forma irónica, o caricaturista desmonta, um a um, os mecanismos repressivos: pede para Ihe baterem, "como manda a lei"; para lhe porem palha no chão e um pedregulho como almofada, como faziam aos outros; para Ihe darem o pão negro dos condenados; e para o torturarem, com os percevejos que afligiam os presos. Implora ainda, como recreio, "uma aranha para domesticar" (o marquês de Valada) e pede um dos sete instrumentos de Fontes Pereira de Melo". Por último, deseja sofrer "sob os ferros de elrei" aquilo que "sofreu Shakespeare sob a pena do mesmo rei", com a última tradução de Hamlet. A imagem mostra D. Luís a bater em Shakespeare e o caricaturista, coagido por Rodrigues Sampaio, a cumprir a sua pena. Bordalo torna-se personagem das ficções teatrais que encena nas páginas dos periódicos. Com grande eficácia, o caricaturista representa as imposições censórias como normas sem sentido, destituídas de qualquer lógica, através do mundo ridiculo e de nonsense que coloca diante do observador

$\mathrm{Na}$ apropriação que faz do teatro, a sátira bordaliana socorre-se das cenas teatrais que o público melhor conhece o que reforça a dimensão comunicativa das imagens. Na "Ária da Favorita", Rafael Bordalo escolhe novamente uma cena muito conhecida, de grande intensidade dramática para ridicularizar a fúria persecutória do juiz Veiga contra o jornalismo, simbolizado em Fernando, o monge da ópera de Donizetti, em cena nas temporadas de 1899-1900 e 1900-1901, no teatro de São Carlos e no Coliseu dos Recreios. Num "cenário" enquadrado por morcegos e mochos (novamente se convoca o cemitério...), a personagem surge a cantar a cavatina "Spirto gentil", "a peça indiscutivelmente mais popular e apreciada de toda a ópera" ${ }^{2}$, de que o caricaturista transcreve também a partitura. É grande a similitude entre a representação caricatural da figura e a postura convencional dos tenores nesta cena e que as fotografias documentam: a mesma posição corporal, o mesmo olhar elevado aos céus, o mesmo figurino. A sátira perpassa pelos pormenores da imagem: o olhar do monge dirige-se para o morcego e, na orelha, está a pena ameaçada. Compõem o cenário os

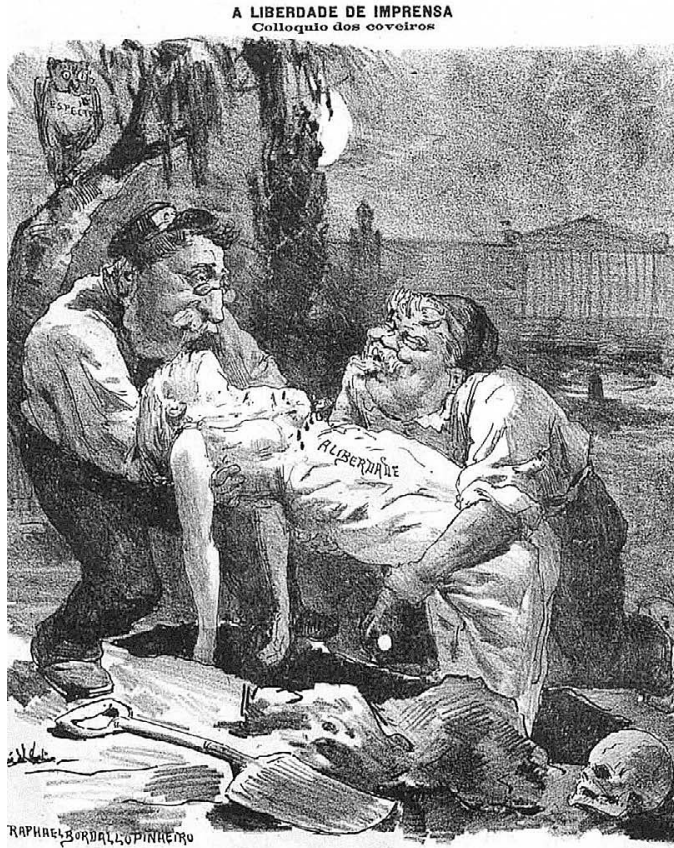

- Achas quo ostará bem morta?
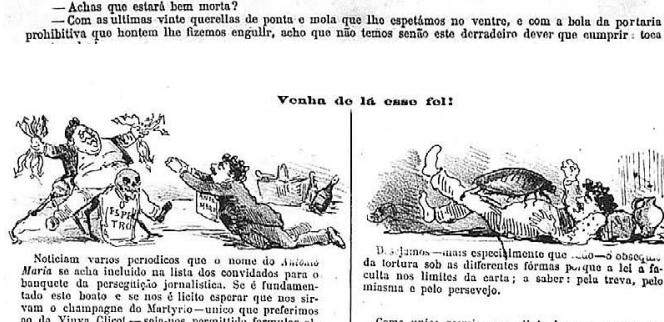

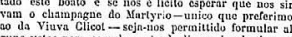

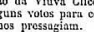

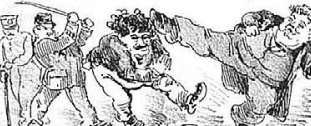

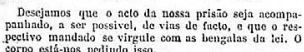

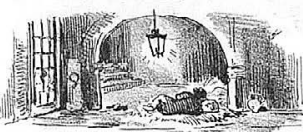

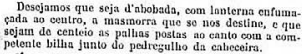

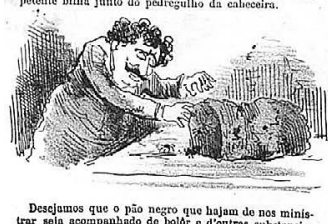

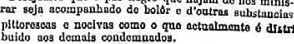
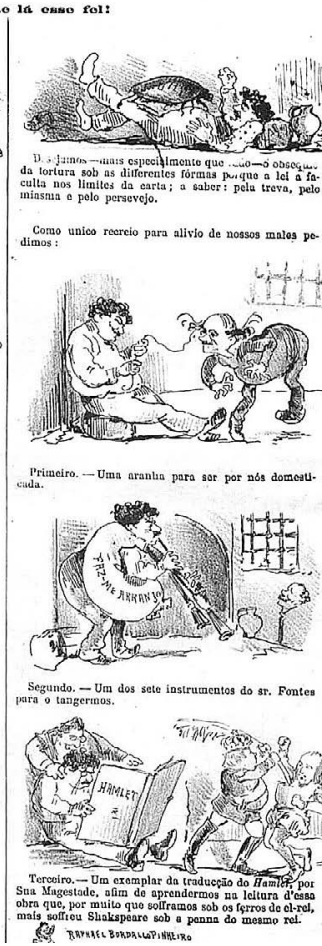

vários símbolos da morte: a cruz, os ciprestes e os monges penitentes dos "direitos do homem". Na legenda, às exclamações arrebatadas de Leonor "Fernando! Mio Fernando!", que antecedem os derradeiros momentos de vida da personagem, segue-se uma outra "A liberdade de imprensa!". Esta, na época, agonizava...

Na construção desta cena teatral, Bordalo não se serve apenas das passagens da ópera. Cita também Talvez te escreva, uma revista estreada com enorme sucesso, e uma canção popular, "Lindos olhos tem o mocho". Alguns pormenores restam enigmáticos: os caranguejos - que significarão? Passado mais de um século e desaparecido 


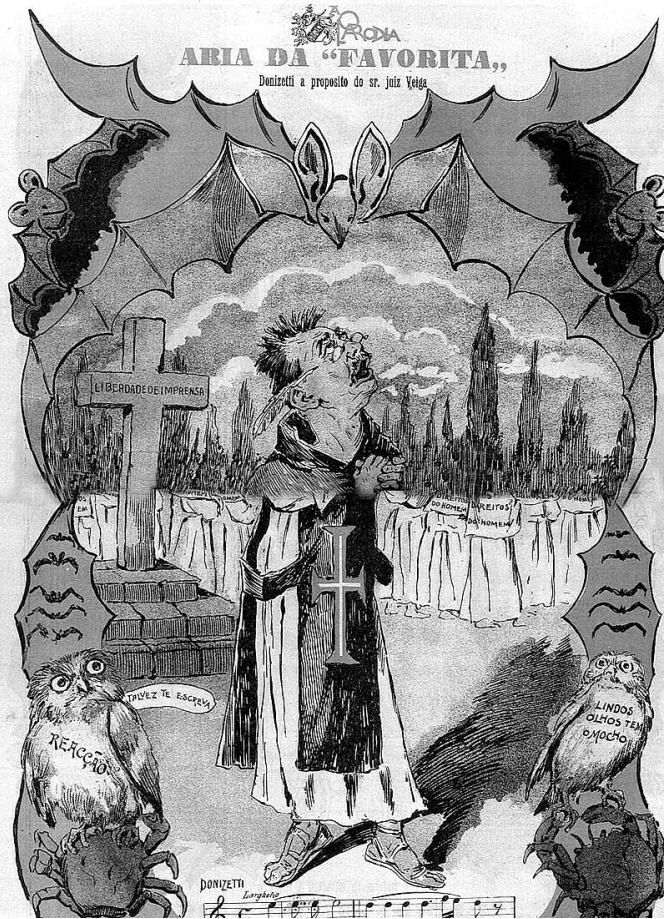

o contexto são alusões de difícil decifração. Como o teatro, a caricatura é uma arte efémera. Vive e alimenta-se do facto imediato, deixando de ser actuante quando desaparece a realidade que a origina. Neste caso, perdura como objecto artístico a que a arte teatral serve de modelo.

De uma outra natureza é a caricatura, da autoria de Manuel Gustavo Bordalo Pinheiro, contra a proibição da peça A noite do Calvário ( publicada em A paródia, 13 de Março de 1901 [p. 8]). É uma imagem que parodia as representações plásticas religiosas sobre a morte de Cristo no Calvário, tomando o título da peça à letra e dando-Ihe expressão visual. Crucificado, no lugar de Jesus Cristo, está Marcelino Mesquita, o dramaturgo e, ao lado, está inscrita a sua proclamação:

Este protesto dirige-se à opinião dos que me não conhecem; dispensa explicações inúteis ante o facto; cala as cavilosas piedades dos hipócritas, e prova, desgraçadamente, que em Portugal, onde o bom senso morreu, a liberdade agoniza.

No topo da cruz, lê-se "Teatro de D. Maria II", onde a peça iria ser representada. Ao lado do escritor, também crucificados, estão representados simbolicamente os dois "ladrões": à esquerda, o representante do governo civil, responsável pela proibição e, à direita, o comissário dos teatros, conivente com a medida. Apesar de a fonte primeira desta imagem ser a pintura sacra, o observador tem também percepção da teatralidade neste desenho. Em primeiro plano, as figuras da censura e da liberdade parecem contracenar: a primeira, de tesoura na mão, símbolo dos cortes na peça, tapa o rosto, deixando apenas à vista um olho furibundo; a outra, de mãos postas, parece implorar-Ihe compaixão.

Os desenhos analisados parecem indicar que a teatralidade destas imagens está relacionada com dois tipos de factores: com a sua fabricação e com a percepção do observador. No que respeita à fabricação dos desenhos de Rafael Bordalo, neles estão presentes o repertório

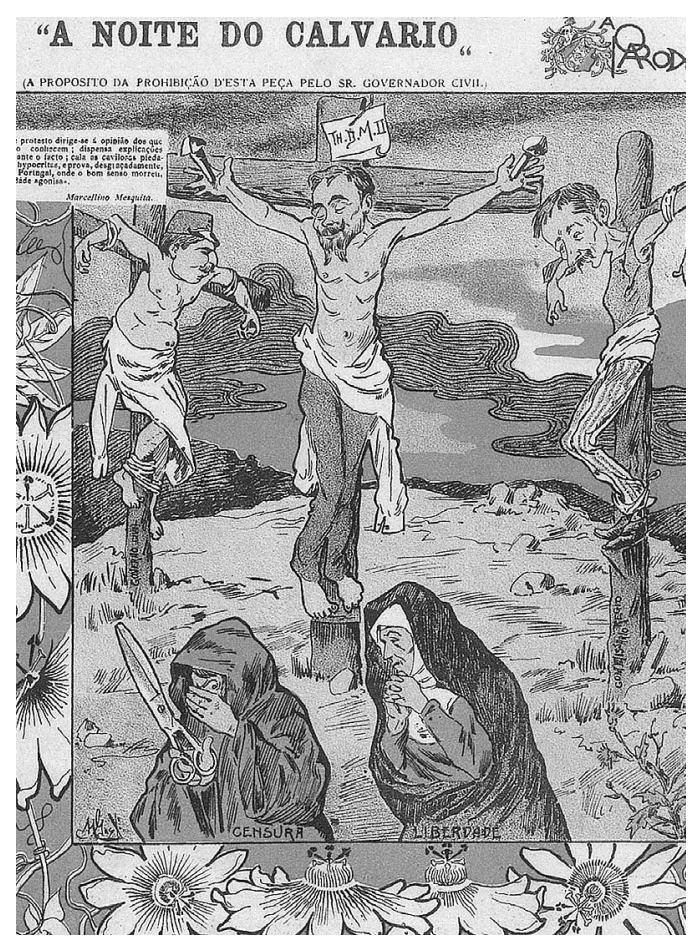

"Ária da Favorita", de Rafael Bordalo Pinheiro, publicada em A paródia, 19 de Setembro de1900 pp. 284-285.

"A noite do Calvário", de Manuel Gustavo Bordalo Pinheiro, A paródia, n.․ 61, 13 de Março de1901, p. 88.

teatral da época e uma determinada maneira de pensar e de encenar o teatro. Cada uma a seu modo, todas as imagens assinalam a dupla entidade - actor/ personagem - sem a qual não existe representação teatral. As imagens representam corporalidades, posturas e uma gestualidade que sinalizam o "fingimento" próprio do teatro, que o público está habituado a ver em palco. Olhando para as personagens, o observador percepciona posturas e gestos que não são os do quotidiano, daí a tendência para os interpretar como algo composto, como algo "fingido", que convoca um protótipo de "representação". É a partir da sua própria experiência corpórea que o espectador de teatro percepciona a corporalidade que vê no palco e a entende como teatral ${ }^{3}$, tendo a percepção que, apesar das semelhanças com o quotidiano, está perante uma construção artística. 0 mesmo se passa em relação à caricatura.

Muita da eficácia da sátira bordaliana decorre da apropriação que é feita de determinadas peças de teatro e de cenas particularmente fortes e impressivas, de grande impacto nos espectadores, um teatro que se converte em arma do desenho satírico na luta contra a censura, através de metáforas certeiras algumas das quais, um século mais tarde, Cesariny retomará significativamente no seu "Elogio do Principe da Dinamarca": "Coitado do Hamlet /

Assassinado / Empurrado /Para o sepulcro que é (...) / Coitado do que ele vê / Crimes / Espectros / Correctos / Coitado do Hamlet" (Cesariny 2005: 61).

\section{Referências bibliográficas}

IVENS, Diogo (1942), Hamlet e Antero, Lisboa, Editorial Império. CESARINY, Mário (2005), Manual de prestidigitação, Lisboa, Assírio \&t Alvim. 